\title{
BraidotTi, R (2002). METAMORPHOSES: TOWARDS A MATERIALIST THEORY OF BECOMING. Reino Unido: Polity Press
}

\author{
Helena Ferreira
}

Rosi Braidotti nasceu na Itália e cresceu na Austrália, possuindo assim dupla nacionalidade. Foi na Austrália, em Canberra, no ano de 1977, que iniciou a sua formação, na Australian National University, tendo sido galardoada com a University Medal in Philosophy e o prémio University Tillyard. Realizou o doutoramento na Sorbonne, onde se formou em Filosofia em 1981. Em 1988, foi nomeada professora na University of Utrecht, na Holanda e em 1995 assumiu o cargo de Directora Fundadora da Escola Holandesa de Investigação em Estudos da Mulher, cargo que ocupou até 2005. Braidotti foi uma pioneira nos estudos sobre as mulheres europeias e é actualmente uma figura mundial em estudos de género e teoria crítica. A sua área de investigação situa-se nos campos da filosofia continental e epistemologia, teorias feministas e de género e no pensamento pós-estruturalista.

"I am rooted, but I flow", foi a frase de Virgínia Woolf que Braidotti seleccionou para dar início ao prólogo desta obra. Ter raízes, mas voar, fluir, é a ideia que atravessa este livro filosófico, que a autora considera "um mapa que traça a trajectória de mudanças, de transformações e de devires" (p. 10). Partindo do princípio de que a única constante que marca este início do Século XXI é a mudança, então o desafio será pensar sobre processos, muito mais do que sobre conceitos, uma vez que a real questão não reside em saber quem somos, mas sim em quem queremos converter-nos. Para esse efeito, é necessário explorar a necessidade de apresentar novas figurações, representações alternativas e localizações sociais desse sujeito nómada híbrido em processo de devir. Estas figurações são "mapas vivos" que tentam traçar uma cartografia das relações de poder que definem as posições das entidades dinâmicas e em mudança, e que também podem ser úteis para identificar possíveis lugares estratégicos de resistência. Tendo como base, a sua visão nómada de subjectividade, e recorrendo às filosofias da diferença de Gilles Deleuze e de Luce Irigaray, a autora proporciona uma cartografia da actualidade no que se refere a questões culturais, políticas, epistemológicas e éticas, enfatizando o potencial criativo e construtivo. Influenciada pela filosofia da tradição francesa que nasce no século XVIII e que é continuada por Bachelar, Canguilhem, Foucault, Lacan, Irigaray e Deleuze, que prioriza a questão da sexualidade, do desejo e do imaginário erótico, Braidotti "ziguezagueia" através dos conceitos: encarnação, imanência, diferença sexual, rizoma, memória e permanência ou sustentabilidade. Avisa, no entanto, as suas leitoras e leitores que não devem pensar as percepções que retiram destes conceitos como uma suposta verdade. 
Bem pelo contrário, devem ser vistos como algo que os impulse em "múltiplas direcções abertas por uma série de experiências extratextuais (p. 10).

No primeiro capítulo, Braidotti adverte que a história europeia da filosofia sempre viu a "diferença", como um elemento pejorativo, colonizado por formas de pensamento hierárquicas e de exclusão. Portanto, um dos objectivos do feminismo consiste em eliminar a conotação pejorativa que se instituiu sobre a ideia de "diferença". O sujeito do feminismo hoje, já não é a Mulher como um espelho do homem, mas um sujeito sexuado e "encarnado", complexo, multiestratificado e rizomático, plenamente consciente da existência de desigualdades e empenhado em afirmar a diversidade e a diferença como valores positivos e alternativos. As novas figurações de subjectividade feministas, conscientes do seu posicionamento de sujeitos "encarnados", vão muito além das metáforas de mulheres que actuam como elementos institucionais, sinais e símbolos do poder do discurso dominante conceptual. Como forma de dar sentido à diversidade existente entre as mulheres no seio da categoria "diferença sexual", entendida como o oposto binário do sujeito falogocêntrico, Braidotti propõe uma política de localização associada à noção de responsabilidade epistemológica e política. Esta política de localização implica um processo de tomada de consciência que requer um despertar político, dependente também da intervenção dos outros, ou seja, implica delinear cartografias do poder baseadas numa forma autocrítica onde o sujeito elabora uma narrativa crítica e genealógica de si, na medida em que interage com os outros e dependem do escrutínio externo, permitindo assim que as análises dos "encarnados" aclarem e transformem o conhecimento que cada um tem de si e do mundo. Um sentido de responsabilidade pelas próprias localizações vai fazer com que as figurações de uma subjectividade feminista alternativa, como a lésbica, o cyborg, a outra inapropriada, a feminista nómada, etc., sejam diferentes das metáforas clássicas, porque expressam cartografias materialmente inscritas no sujeito e, neste sentido, presumem um exercício de auto-reflexão em vez de uma relação parasitária num processo de metaforização dos "outros". Recorrendo aos filósofos pós-estruturalistas da diferença, Foucault, Irigaray e Deleuze, a autora focaliza-se na estrutura material e sexualizada do sujeito, que se encontra intimamente ligada com as relações sociais e políticas. A sexualidade, sendo uma instituição social e simbólica, material e semiótica, torna-se na principal localização do poder, segundo uma dinâmica complexa que abrange micro e macro relações. Segundo o modelo dualista, o sexo é a alocação social e morfológica da identidade e a forma erótica adequada para os sujeitos socializados e o género é um termo genérico que descreve o tipo de mecanismos de poder que participam na complexa interacção de forças do sistema dualista polarizado. Braidotti, reconhece, então, a importância do transcendental sensível, que situa o sujeito feminino "encarnado" num espaço entre a transcendência e a imanência, conectando, assim, o sujeito feminino com uma série de diferenças dentro de si mesma e entre ela e os outros ou outras.

O segundo capítulo propõe uma leitura feminista sobre o trabalho de Deleuze que, para além de apresentar uma grande empatia com as questões da diferença, sexualidade e transformação, ainda investe de força positiva o lugar do feminino. Para Deleuze, "o 
"outro" não é a marca emblemática e, invariavelmente, vampirizada de alteridade, como na filosofia clássica. Também não é um "outro" convertido em fetiche e necessariamente alterizado, como na desconstrução. É um horizonte móvel de intercâmbios e de devires para o qual se movem os sujeitos não unitários da pós-modernidade e que por sua vez, os faz mover-se" (p. 69). No que diz respeito, à identidade de género, o filósofo francês não se limita a uma oposição dicotómica entre uma posição de sujeito masculino e outra feminina, mas sim a uma multiplicidade de posições de sujeito sexuadas, em que as diferenças entre elas assinalam diferentes linhas de devir, numa trama de conexões rizomáticas. Sendo assim, o sujeito está dotado de múltiplas sexualidades. Deleuze foi um dos maiores criadores de figurações alternativas e pós-metafísicas do sujeito: corpo sem órgãos, devir, rizoma. A sua figuração central é o devir minoritário, o nómada, o molecular, o devir mulher, ocupando o espaço da marginalidade dinâmica, isto é, traçando trajectórias rápidas de mudanças do centro, confluído na subjectividade do homem, macho ocidental, para a periferia. Assume assim, tal como Irigaray, que não existe o devir minoritário do homem, uma vez que este é o referente privilegiado da subjectividade, representando o maioritário, "o coração morto do sistema", e que o devir mulher é um passo fundamental no processo do devir para ambos os sexos. É ainda neste capítulo que Braidotti introduz o conceito de "met(r)amorfoses" de Lichtenberg, que a mesma define de "o devir de limiares de fronteiras" (p. 114). Lichtenberg, adaptando livremente a teoria de Deleuze, procura desestabilizar a maquinaria edipiana, propondo uma "matriz" que entende como um espaço uterino que se encontra desterritorializado e que por isso pode gerar o feminino virtual como uma diferença positiva. Este processo gera met(r)amofoses, porque aponta à multiplicidade, à pluralidade e ao mesmo tempo estabelece conexões pré-natais entre sujeitos não unitários. Esta coexistência de opostos coloca-se contra a totalidade e a "mesmidade" do histórico significante fálico. A "met(r) amorfose" empossa de poderes significantes a fluidez e os fluxos. A ilusão de que existe um caminho verdadeiro ou apenas um centro de resistência será substituída por um longo processo de aprendizagem, para experimentar transformações pontuais, através de repetições infinitas que assegurará, em troca, um constante fluxo de met(r)amorfoses. O devir minoritário, molecular, mulher não é um fim em si mesmo, mas um espaço sumamente diferenciado e turbulento de devires múltiplos e dissimétricos.

No terceiro capítulo, Braidotti, propõe-se verificar a sua tese de que diluir a sexualidade fálica e a identidade em fluxos indiferenciados pode adaptar formas e velocidades distintas em função de localizações geopolíticas, sexuais e de outra índole, no caso do devir animal. Para tal, debate as ideias de Deleuze, dando o exemplo da escrita, que este autor, fiel à sua visão anti-falogocêntrica da criatividade, considera uma espécie de devir animal, observando que as escritoras e escritores vivem em permanente estado de alerta, constantemente em tensão devido ao esforço que fazem para cativar e reter os sinais que advêm do seu plano de contacto imanente com outras forças, como os animais. Contrapõe este exemplo com a personagem principal de "La Passion", de Clarice Lispector, segundo G. H., que demonstra que uma mulher branca e acomodada vai perdendo gradualmente a sua personalidade, tal como é definida socialmente, acabando por ser 
parte de um sistema de espaço e de tempo densamente entrançados. Esta personagem abarca a multiplicidade de possibilidades que habitam no seu interior. "Deixa de ser um indivíduo, uma pessoa e converte-se numa partícula de matéria viva, esta é carne inteligente que pode pensar e recordar, um exemplo vivo de imanência radical, desumana, pós-humana e, ao mesmo tempo demasiado humana" (p. 161). Braidotti defende que comparando estas duas narrativas, a análise de "devir/mulher/insecto" de Deleuze se torna inadequada devido à sua aproximação sexualmente indiferenciada e questiona se Deleuze não se encontra "localizado" num lugar bastante perto da reivindicação feminista da revalorização de uma subjectividade feminina alternativa. A última palavra, segundo a autora, sobre o processo de transformação radical das mulheres, sobre o devir mulher ou o devir insecto, pode vir da prática da diferença sexual como um projecto político e conceptual em que o núcleo dessas práticas transformadoras são as "met(r) amorfoses". Conclui ainda que o entrelaçado de bios, zoe e technos é cada vez mais evidente no imaginário cyber-teratológico da pós-modernidade, sendo por isso necessário elaborar figurações de subjectividade políticas para esse imaginário tão incerto e perturbado pelas grandes mudanças e variações.

Nos dois últimos capítulos, a autora destaca alguns aspectos da cultura contemporânea que são particularmente recorrentes e populares e que vão desde o fascínio pela tecnologia e biotecnologia, ao gótico e o monstruoso, que muitas vezes acompanham as representações sociais dos fenómenos simbólico-culturais. No início do quarto capítulo, começa, no entanto, por recapitular os seus objectivos, reforçando que as figurações evocam as mudanças e as transformações que se encontram em marcha no contexto "g-local" das sociedades avançadas e que o modelo rizomático ou nómada implica reflectir sobre processos e não pontos fixos. Quanto à diferença, refere que esta é ao mesmo tempo o problema e a solução e que se interpreta segundo a linguagem da monstruosidade, uma vez que se queremos encontrar ilustrações culturais apropriadas das mudanças e das transformações que ocorrem no presente, devemos voltar-nos para os géneros "menores", para os marginais e híbridos, como a ficção científica, o terror e o ciberpunk. A ficção científica permite um deslocamento da nossa visão do mundo fora do epicentro humano e consegue estabelecer um continuum com o mundo animal, mineral, vegetal, extraterrestre e tecnológico, apontando assim para um igualitarismo pós-humano e biocentrado. A autora defende que a sua rejeição a uma posição sexual indiferenciada, significa que valoriza muito os processos de mudança e transformação como formas de actualizar um feminino virtual numa rede de interconexões com outras forças, entidades e actores. A este feminino aberto e multiestratificado, denomina de met( $r$ amorfoses, como já foi referido. "A matriz não é de carne nem de metal, nem destino nem teleologia: é movimento, tanto em termos espaciais, como temporais" (p. 206). No quinto capítulo, a questão fundamental é a cibertecnologia. O imaginário contemporâneo cibertecnológico expressa simultaneamente duas tendências políticas contraditórias. Como resposta reactiva ou negativa, expressa o medo e as ansiedades da maioria "encarnada" na posição de sujeito dominante do homem branco, heterossexual, urbanizado, titular de um património e falante de uma língua estandarte num movimento histórico em que 
as suas certezas se estão a desmoronar. Como gesto afirmativo ou potenciador, expressa as paixões políticas de todos os sujeitos, inscritos na minoria, que optaram pelas políticas transformadoras e pelos processos de devir. Desde o século XIX, que a cultura ocidental enfrenta a ameaça ou promessa da meta(l)morfose, ou seja de um genérico devir máquina e actualmente, o processo de transformação do sujeito segue o seu curso. Através de met(r)amorfoses ou met(l)amorfoses, surge-nos um sujeito monstruoso, híbrido e belo, que parece, sente e sonha de modo incomum, não sendo isso nenhuma catástrofe, bem pelo contrário, porque abre novas formas de vida de coabitação entre os humanos e os outros. A autora recomenda que se adopte uma posição nómada, porque se fluímos estamos enraizados e enraizadas.

Helena Ferreira, licenciada em Psicologia Organizacional — Vertente Recursos Humanos pelo Instituto Superior de Línguas e Administração de Bragança, pós-graduada em Gestão das Organizações sem Fins Lucrativos pela Porto Business School, Mestre em Ciências da Comunicação - Publicidade e Relações Públicas pela Universidade do Minho e doutoranda do programa doutoral em Estudos Culturais em parceria entre a Universidade de Aveiro e a Universidade do Minho. Tem publicado alguns artigos e realizado comunicações, a maioria em parceria com outros autores, na área da comunicação. É investigadora voluntária na Agência Irenne de Comunicação e Educação para a Cidadania e Igualdade de Género.

E-mail: hcarla@ua.pt

Universidade de Aveiro / Universidade do Minho Instituto de Ciências Sociais, Campus de Gualtar 4710-057 Braga Portugal

* Submetido: 16-02-2015

$*$ Aceite: 20-04-2015 